\title{
ANALISA KEBUTUHAN ENERGI MINIMUM UNIVERSITAS LANCANG KUNING
}

\author{
Masnur Puta Halilintar ${ }^{1}$, Monice $^{2}$ ) \\ Jurusan Teknik Elektro, Fakultas Teknik Unilak \\ Jl. Yos Sudarso Km.8 Rumbai \\ ${ }^{1}$ masnur@Unilak.ac.id; ${ }^{2}$ Monice@Unilak.ac.id
}

\begin{abstract}
The need for electrical energy to support the vision of the University of Lancang Kuning Unggul in 2030 is a necessity. Excellence according to the assessment standards of the Directorate of Higher Education in 2015 following the results of the ranking of universities in Indonesia is determined by four categories. First; quality of human resources; Second; quality management; Third; quality of student activities; and Fourth; quality research and scientific publications. Activities of these four criteria come from campus activities undertaken by lecturers, students and campus management associated with electrical energy. It is undeniable that it is impossible that research activities of lecturers, campus management and student activities are not related to electrical energy. Evidently at this time, Unilak experienced energy deficit and become a problem that resulted in not optimum teaching and learning process, management activities related to IT devices. Referring to Permenristek No15 of 2015 on Lecturer and Student Ratio rules and Unilak's vision of 2030 superior need to be studied the minimum energy consumption requirement at University of Lancang Kuning to maintain optimal achievement of the rating criteria. In the initial phase begins by collecting data and inventory Asset energy use in each Faculty, and other facilities then make estimates of power usage according to exixting data. The results show that the energy used today is still below the standard energy that is convenient for the activities tridharma college. The minimum installed energy available for an average room is 1,160 wat for a room with a size of $64 \mathrm{~m} 2$. With conditions like this
\end{abstract}


should be re-calculated to get the ideal minimum energy to support the activities of tri dharma college to Unilak Unggul 2030

Keywords: Energy; efficiency; excellence. 


\section{PENDAHULUAN}

Penggunaan energi listrik Universitas Lancang Kuning perbulan rata-rata pada angka 40-65 juta. Jumlah ini untuk melayani kebutuhan sembilan Fakultas dengan dua puluh program studi strata satu dan dua program studi strata dua dan beberapa gedung pendukung lainnya yang memiliki rekening terpisah seprti Rusunawa dan Gedung PKM Unilak.

Tiga fakultas dengan jumlah mahasiswa tertinggi adalah Fakultas Hukum; 1.952 mahasiswa, Fakultas Ekonomi, 1.252 mahasiswa dan Fakultas Ilmu Administrasi; 1.027 mahasiswa (forlap dikti, 2016) memberikan kontribusi pemakaian energi terbesar. Kebijakan universitas menambah trafo baru untuk penggunaan sendiri fakultas dimaksud adalah solusi jangka pendek untuk mengatasi devisi penggunaan energi listrik.

Fakultas Teknik, Fakultas Kehutanan dan Fakltas Pertanian juga memberikan kontribusi pemakaian energi cukup besar yang disumbang oleh keberadaan laboratorium di tiga fakultas tersebut. Kontribusi pemakaian energi listrik ditentukan oleh berbagai elemen diantaranya jumlah mahasiswa, jenis peralatan dan budaya penggungaan energi listrik. Di fakultas Teknik, prodi Teknik Arsitektur memiliki lebih kurang empat puluh unit perangkat komputer, Teknik Elektro dengan laboratorium dasar dan laboratorium lanjutan. Dalam operasinya laboratorium Teknik Elektro tidak bisa beroperasi tanpa energi listrik untuk menggerakkan mesin-mesin listrik dan alat alat ukur listrik. Demikian juga Jurusan Teknik Sipil, beberapa peralatan laboratorium juga tidak dapat difungsikan tanpa energi listrik.

Dua pertimbangan yang menjadi dasar penelitian ini dilakukan adalah, pertama; upaya melakukan efisiensi penggunaan energi listrik. Biaya energi listrik perbulan yang harus disediakan oleh Unilak pada kisaran 40-65 juta tersebut, dihitung mahal jika dibandingkan dengan pos pembiayaan lain, walaupun sesungguhnya angka tersebut terhitung normal dibandingkan dengan perguruan tinggi lain. kedua; Perubahan Akreditasi beberapa prodi dilingkungan Universitas Lancang Kuning dari beberapa prodi yang Akreditasi sebelumnya $\mathrm{C}$ menjadi Berakreditasi B. Hal ini diprediksi akan meningkatkan minat calon mahasiswa untuk masuk di Universitas Lancang Kuning ditahun-tahun yang akan datang, sehingga diperlukan pengelolaan menajemn energi optimal dalam rangka pengembangan Universitas Lancang Kuning.

Perhitungan kebutuhan energi minimum pada sembilan Fakultas di Universitas Lancang Kuning memanfaatkan teori luminasi yang nantinya dapat diketahui kebutuhan Pencahayaan dalam setiap ruangan pada masing-masing Fakultas. Pada Fasilitas penunjang lainnya estimasi dapat dihitung menggunakan metode regresi berdasarkan data pemakaian energi (KWh meter PLN) dari tahun tahun sebelumnya.

\section{TINJUAN PUSTAKA}

\section{Kebutuhan Beban (Load Demand)}

Kebutuhan adalah perbandingan antara kebutuhan maksimum (beban puncak) terhadap total daya tersambung. Jumlah daya tersambung adalah jumlah dari daya tersebut dari seluruh beban dari setiap konsumen, 
Kebutuhan Beban pada masing-masing Fakultas tergantung Jumlah Ruangan, Fasilitas yang dipakai dan standar penggunaan alat buat penunjang kegiatan belajar mengajar. Ruangan yang ada mengikuti perkembangan existing pembangunan Unilak hingga Bulan November 2016

\section{Intensitas Konsumsi Energi (IKE)}

Intensitas Konsumsi Energi (IKE) adalah istilah yang digunakan untuk menyatakan besarnya jumlah penggunaan energi tiap meter persegi luas kotor (gross) bangunan dalam suatu kurun waktu tertentu (Budi Agung Raharjo).

Penggunaan energi dapat dihitung jika diketahui:

1. Rincian luas bangunan gedung dan luas total bangunan gedung (m2).

2. Konsumsi Energi bangunan gedung per tahun (kWh/tahun).

3. Intensitas Konsumsi Energi (IKE) bangunan gedung per tahun (kWh/m2/tahun)

4. Biaya energi bangunan gedung $(\mathrm{Rp} / \mathrm{kWh})$

$$
\operatorname{IKE}\left(\frac{k W H}{m^{2}}\right)=\frac{\text { Total konsumsi enerti }(k W h)}{\text { luas lantai total }\left(m^{2}\right)} \ldots \text { (7) }
$$

\section{Teori Luminasi}

Empat istilah standar dalam pencahayaan beserta satuannya antara lain:

1. Arus cahaya (luminous flux) adalah banyak cahaya yang dipancarkan ke segala arah oleh sebuah sumber cahaya per satuan waktu (biasanya per detik), diukur dengan Lumen.

2. Intensitas cahaya (luminous intensity) adalah kuat cahaya yang dikeluarkan oleh sebuah sumber cahaya ke arah tertentu, diukur dengan Candela.

3. Iluminan (illuminance) adalah banyak arus cahaya yang datang pada satu unit bidang, diukur dengan Lux atau Lumen $/ \mathrm{m}^{2}$, sedangkan prosesnya disebut iluminasi (illumination) yaitu datangnya cahaya ke suatu objek.

4. Luminan (luminance) adalah intensitas cahaya yang dipancarkan, dipantulkan dan diteruskan oleh satu unit bidang yang diterangi, diukur dengan Candela $/ \mathrm{m}^{2}$, sedangkan prosesnya disebut luminasi (lumination) yaitu perginya cahaya dari suatu objek.

\section{METODE}

\section{Waktu dan Lokasi Penelitian}

Penelitian dilakukan di Universitas Lancang Kuning Pekanbaru. Pengambilan data dilakukan dengan mensurvey masing-masing fakultas yang ada di Universitas Lancang Kuning. Mulai dari ruangan kuliah, ruang dosen, labor, ruang dekan,wakil dekan dan ruangan yang ada di masing-masing fakultas yang memanfaatkan energi.

\section{Peralatan, perlengkapan yang digunakan}

Untuk melakukan penelitian dibutuhkan beberapa peralatan dan instrument pengukuran parameter listrik antara lain;

1. Lux meter

2. Meteran

3. Kamera

\section{Rancangan Penelitian}

Penelitian ini menggunakan rancangan kualitatif. disertai bantuan analisis data lapangan untuk melihat alokasi pengunaan beban pemakaian energi. Untuk melihat pertumbuhan pengembangan energi digunakan data prediksi pertumbuhan mahasiswa bagian Perencanaan dan Pengembangan Unilak.

\section{Tahapan Penelitian}


Dalam penelitian ini akan dilakukan tahapan sebagai berikut:

Tahapan persiapan. Pada tahapan ini dilakukan pengumpulan data awal sekaligus proses pendekatan dengan objek penelitian serta mempersiapkan referensi pendukung penelitian. Data awal yang dibutuhkan adalah:

Menghitung Kebutuhan Energi, secara umum kebutuhan energi listrik Universitas Lancang Kuning terdiri dari:

\section{Kebutuhan Penerangan Ruangan}

a. Ruangan Kerja

b. Ruangan Kelas

c. Ruangan Perpustakaan

d. Ruangan Laboratorium

e. Ruangan organisasi kemahasiswaan

f. Ruangan fasilitas pendukung lain

g. Penerangan Luar Ruangan

\section{Kebutuhan Peralatan listrik}
a. Bola Lampu
b. Komputer
c. Printer
d. Mesin Air
e. Kulkas
f. Pemanas air
g. AC
h. CC TV
i. Infocus
j. Mesin dan Peralatan Laboratorium
k. TV
1. Finger Print
m. Alat cas HP

\section{HASIL}

Dari data primer yang dikumpulkan didapatkan data existing beban, luas ruangan, dan luminasi pencahayaan dalam ruangan. Data yang didapatkan adalah sebagai berikut:

\section{Gedung Fakultas Ilmu Komputer}

Bangunan Fakultas Ilmu Komputer (Fasilkom) merupakan bangunan baru yang letaknya bersebelahan dengan Fakultas Keguruan dan Ilmu Pendidikan (FKIP). Dari data primer yang dikumpulkan banyaknya ruangan di gedung baru Fasilkom adalah 14 ruangan dan apabila di total keseluruhan luas ruangan lebih kurang enam ratus meter persegi $\left(600 \mathrm{~m}^{2}\right)$ dengan jumlah beban total keseluruhan adalah 17.778 (watt).

\section{Gedung Fakultas Keguruan dan Ilmu Pendidikan (FKIP)}

Terletak diantara Fakultas teknik dan dan Fasilkom. FKIP bangunanyya berlantai 2 dengan total jumlah rungan adalah dua puluh empat ruangan dengan luas tujuh ratus dua puluh sembilan meter persegi $\left(729 \mathrm{~m}^{2}\right)$ dengan jumlah beban total keseluruhan adalah 31.134 (watt).

\section{Gedung Fakultas Kehutanan}


Fakultas kehutanan terdiri dari dua lantai dengan jumlah rungan dua puluh ruangan dengan luas sembilan ratus duapuluh meter persegi $\left(920 \mathrm{~m}^{2}\right)$. Jumlah daya yang terpasang dengan jumlah total keseluruhan sebesar 22.147 watt.

\section{Fakultas Pertanian}

Fakultas Pertanian terdiri dari dua lantai dengan jumlah rungan 19 ruangan dengan Jumlah daya yang terpasang dengan jumlah total keseluruhan sebesar 15.689 watt

\section{Fakultas Teknik}

Fakultas Teknik terdiri dari dua lantai dengan jumlah rungan 17 ruangan dengan Jumlah daya yang terpasang dengan jumlah total keseluruhan sebesar 33.769 watt

\section{Fakultas Ekonomi}

Fakultas Ekonomi dengan bangunan baru memiliki ruangan cukup banyak yaitu 31 raungan dengan jumlah daya keseluruh adalah 21.883 watt.

\section{Fakutas Ilmu Administrasi}

Fakultas Ilmu Administrasi memiliki ruangan sebanyak 22 ruang dengan jumlah daya keseluruh adalah 19.536 watt

\section{Gedung Rektorat}

Gedung rektorat memiliki ruangan cukup banyak karena sebagian ruangan masih digunakan oleh Fakultas Ilmu Administrasi dan Fakultas Ilmu Budaya. Jumlah ruangan keseluruah adalah 37 ruangan. Jumlah daya keseluruh adalah 40.567 watt.

\section{Fakultas Hukum}

Fakultas memiliki bangunan gedung bergabung antara S1 dan S2 dengan jumlah gedung 3 unit gedung. Total ruangan keseluruhan adalah 37 raungan dengan jumlah daya keseluruhan adalah 22.917 watt.

\section{Gedung Perpustakaan}

Gedung perpustakaan tidak memiliki ruangan banyak akan tetapi sesuai dengan fungsinya gedung perpustakaan memiliki ruangan terbuka yang luas dengan total daya 11.258 watt.

\section{Mesjid}

Masjid hanya memiliki ruangan utama dan tempat wuduk dengan jumlah daya 491 watt.

Rincian ruangan dan total daya terpasang dapat dilihat pada tabel berikut : 


\begin{tabular}{|c|l|c|c|c|c|}
\hline No & \multicolumn{1}{|c|}{ Ruangan } & $\begin{array}{c}\text { Jumlah } \\
\text { Ruangan }\end{array}$ & Luas (m2) & $\begin{array}{c}\text { Jumlah } \\
\text { Beban (titik) }\end{array}$ & Daya (watt) \\
\hline 1 & Fasilkom & 14 & 600 & 156 & 17.778 \\
\hline 2 & FKIP & 24 & 729 & 201 & 31.334 \\
\hline 3 & Fakultas Kehutanan & 20 & 920 & 204 & 22.147 \\
\hline 4 & Fakultas Pertanian & 19 & 878 & 115 & 15.689 \\
\hline 5 & Fakultas Teknik & 17 & 591 & 171 & 33.769 \\
\hline 6 & Fakultas Ekonomi & 31 & 1478 & 392 & 20.819 \\
\hline 7 & Fakultas Ilmu Administrasi & 22 & 1161 & 224 & 19.000 \\
\hline 8 & Rektorat Sisi Kiri & 8 & 544 & 214 & 6.019 \\
\hline 9 & Rektorat Sisi Tengah & 24 & 1220 & 328 & 27.977 \\
\hline 10 & Rektorat Sisi Kanan & 11 & 480 & 86 & 6.671 \\
\hline 11 & Fakultas Hukum S2 & 10 & 905 & 133 & 9.272 \\
\hline 12 & Fakultas Hukum S1 & 23 & 2221 & 316 & 21.995 \\
\hline 13 & Gedung Puskom Lantai 1 & 3 & 576 & 56 & 943 \\
\hline 14 & Gedung Puskom Lantai 2 & 3 & 384 & 84 & 4.924 \\
\hline 15 & Gedung Puskom Lantai 3 & 5 & 364 & 95 & 5.391 \\
\hline 16 & Masjid Al Fatah & 3 & 417 & 48 & 491 \\
\hline & Total & 237 & 13.468 & 2.823 & 244.219 \\
\hline
\end{tabular}

\section{PEMBAHASAN}

Dari data tersebut terlihat bahwa jika dikelompokkan berdasarkan, jumlah ruangan yang digunakan, luas ruangan yang menggunakan energi, jumlah titik beban pada setiap ruangan, dan besarnya daya yang digunakan, maka dapat dikelompok kepada :

1. Jumlah ruangan terbanyak adalah Fakultas Ekonomi dengan jumlah ruangan 31 ruangan, kemudian Fakultas Keguruan dan Ilmu Pendidikan 24 ruangan, Rektorat Sisi Tengah 24 Ruangan, Fakultas Hukum S1 23 ruangan, kemudian berturut Fakultas Ilmu Administrasi, Kehutanan, Pertanian, Teknik, Fasilkom, Rektorat Sisi Kanan, Fakultas Hukum S2, Rektorat Sisi Kiri, Perpustakaan Lantai 3, Perpustakaan Lantai 1, Perpustakaan Lantai 2, dan paling kecil Masjid Al Fatah dengan 3 ruangan.

2. Dari luasan ruangan, Fakulas Hukum S1 dengan luas ruangan tertinggi yaitu $2.221 \mathrm{~m} 2$, Fakultas Ekonomi $1.478 \mathrm{~m} 2$, Rektorat Sisi Tengah $1.220 \mathrm{~m} 2$, kemudian berturut, FIA, Fakultas Kehutunan, Fakulas Hukum S2, Fakultas Pertanian, FKIP, Fasilkom, Teknik, Gedung Perpustakaan Lantai I, Rektorat Sisi Kiri, Retktorat Sisi Kanan, Masjid Al Fatah, Perpustakaan lantai 2, dan Perpustakaan Lantai 3.

3. Jika yang digunakan sebagai indikator ukur adalah Jumlah titik beban, maka Fakultas Ekonomi merupakan fakultas dengan jumlah titik beban tertinggi yaitu 392 titik. Kemudian berturut Rektorat Sisi Tengah 328 titik, Fakultas Hukum S1 316 titik, FIA 224 titik, dan berturut turut Rekotrat sisi kiri, Kehutanan, FKIP, Teknik, Fasilkom, FakultasHukum S2, Pertanian, Perpustakaan Lantai 3, Rektorat sisi Kanan, Perpustakaan lantai 2, Perpustakaan lantai 1, dan Masjid Al Fatah.

Dilihat dari jumlah beban existing (watt), Fakultas Ekonomi merupakan fakultas tertinggi dengan beban existing 20.819. Rektorat sisi Tengah 27.977, Fakultas Hukum S1 21.995, FIA 19.000 dan berturut Rektorat Sisi Kiri, Kehutanan, FKIP, Teknik, Fasilkom, Fakultas Hukum S2, Pertanian, Perpustakaan Lantai 3, Rektorat Sisi Kiri, Perpustakaan lantai 2, Perpustakaan lantai 1, dan Masjid Al Fatah

\section{Rata Rata Beban Energi}

Data existing beban dibandingkan dengan jumlah mahasiwa aktif memperlihatkan angka rasio yang belum sebanding. Perbandingan seprti table berikut: 


\begin{tabular}{|c|l|c|c|c|c|}
\hline No & \multicolumn{1}{|c|}{ Ruangan } & Luas (m2) & Daya (watt) & $\begin{array}{c}\text { Jumlah } \\
\text { Mahasiwa }\end{array}$ & Rasio \\
\hline 1 & Fasilkom & 600 & 17,778 & 640 & 3.60 \\
\hline 2 & FKIP & 729 & 31,334 & 967 & 3.09 \\
\hline 3 & Fakultas Kehutanan & 920 & 22,147 & 330 & 1.49 \\
\hline 4 & Fakultas Pertanian & 878 & 15,689 & 834 & 5.32 \\
\hline 5 & Fakultas Teknik & 591 & 33,769 & 595 & 1.76 \\
\hline 6 & Fakultas Ekonomi & 1478 & 20,819 & 1,252 & 6.01 \\
\hline 7 & Fakultas Ilmu Administrasi & 1161 & 19,000 & 1,027 & 5.41 \\
\hline 11 & Fakultas Hukum S2 & 905 & 9,272 & 346 & 3.73 \\
\hline 12 & Fakultas Hukum S1 & 2221 & 21,995 & 1,977 & 8.99 \\
\hline 13 & Lainnya & 3.985 & 52,416 & - & \\
\hline & Total & 13.468 & 244,219 & 8,431 & 3.45 \\
\hline
\end{tabular}

\section{KESIMPULAN DAN SARAN}

\section{Kesimpulan}

Kebutuhan energi Minimum rata rata sesuai dengan data existing adalah 18,13 watt per meter. Untuk ruang kelas dengan luas $64 \mathrm{~m} 2$ makan kebutuhan daya adalah 1.160 Watt. Angka ini masih dibawah angka standar ideal penggunaan peralatan minimum satu ruangan. Oleh karena perlu penambahan perencanaan ulang agar kebutuhan energi minimum sesuai standar kelayakan agar tingkat kenyaman beraktifitas untuk mendukung Unilak Unggul 2030 dapat tercapai.

\section{Saran}

Penelitian dapat dilanjutkan untuk melakukan studi kelayakan penggunaan energi sesuai dengan standarisasi kebutuhan ruang minimum yang ingin dicapai dalam rangka menuju Unilak Unggul 2030. Rektor perlu menetapkan standar energi minimum dan maksimum yang diizinkan dilingkungan Unilak sesuai dengan hasil perhitungan penelitian lanjutan

\section{REFERENCE}

[1] Budi Agung Raharjo, 2014. Studi Analisis Konsumsi Dan Penghematan Energi Di Pt. P.G. Krebet Baru I.

http://elektro.studentjournal.ub.ac.id/index.php/teub/ article/view/ 183

[2] Harten P, Van, Setiawan. E.1991, Instalasi Listrik Arus Kuat 2. Bina Cipta Bandung

[3] Karnoto. 2006. Audit Energi Listrik Kampus Universitas Diponegoro, UGM, Yogyakarta

[4] SNI 04-02225-2000. Persyaratan Umum Insta- lasi Listrik 2000 (PUIL 2000). Yayasan PUIL. Jakarta.

[5] Zuhal, 1995. Dasar Tenaga Listrik Dan Elektronika Daya,Gramedia 